\title{
KINETIC STUDIES FOR ANILINE HYDROXYLASE AFTER PROLONGED ETHANOL TREATMENT
}

\author{
Suehiro NAKANISHI, Eiko MASAMURA, Miyoko TSUKADA \\ and Riichiro MATSUMURA \\ Department of Pharmacology, Faculty of Medicine, Shinshu University, Matsumoto
}

Received for publication December 10, 1970

In the previous paper, we reported of rats treated chronically with ethanol; that sidechain oxidation of hexobarbital, $\mathrm{N}$-demethylation of aminopyrine and $p$-hydroxylation of aniline in vitro from $9,000 \mathrm{~g}$ supernatant of liver homogenates were identical with those of control rats when ethanol was withdrawn and substituted for tap water 24 hours prior to sacrifice and that, in contrast, the activity of aniline hydroxylase of the rats which continued to ingest ethanol ad libitum up to the time of sacrifice was about 2-fold increased, compared with that of controls, in spite of no change detected in hexobarbital oxidase and aminopyrine demethylase (1).

We also reported that the addition of ethanol in a concentration of $8.5 \mathrm{~mm}$ to the incubation medium caused an inhibition of p-hydroxylation of aniline and that the type of inhibition was, at least superficially, competitive (2).

The present experiments were conducted to examine the kinetic behavior of aniline hydroxylase of rat liver microsomes when rats continued to drink ethanol ad libitum up to the time of sacrifice.

\section{METHODS}

Male Wistar rats weighing $80 \mathrm{~g}$ initially were used. All the rats had free access to adequate solid food (CLEA, CE-2), and the ethanol treatments were the same as in the previous experiments (1). Each animal housed in an isolated room of individual cages, with controlled temperature $\left(22^{\circ} \mathrm{C}\right)$ and illumination $(6: 00$ a.m. to $6: 00 \mathrm{p} . \mathrm{m}$.). In the present experiments, rats were killed 2 months after the experiments began (from July 29 to September 30) and the hepatic aniline hydroxylase activity was assaycd. According to the drinking fluid, the animals were divided into two groups, one drinking tap water (control group), and the other only ethanol (ethanol group). The rats of ethanol group were given $10 \mathrm{v} / \mathrm{v} \%$ ethanol for final one weck prior to sacrifice. The mean ethanol intake of rats a day was about $10 \mathrm{~g}$ per $\mathrm{kg}$ of body weight. For the enzyme assay, the latter was further divided into two subgroups, in one of which ethanol was withdrawn and substituted for tap water 24 hours prior to sacrifice (EtOH-1), whereas in the other the animals continued to drink ethanol ad libitum up to the time of sacrifice (EtOH-2).

\section{Tissue preparation}

In the previous experiments, $9,000 \mathrm{~g}$ supernatant from the liver homogenates of the 
rats in group EtOH-2 was found to contain ethanol in concentrations of 5 to $20 \mathrm{mg} / \mathrm{dl}$. Accordingly, the present experiments kept only to washed microsomes as enzyme source.

Immediately the animals were sacrificed by decapitation between 9 and 10 a.m., the livers were totally removed, washed in ice-cold isotonic $\mathrm{KCl}$ until clear of blood, minced, weighed and the homogenized in 2 vols of ice-cold isotonic $\mathrm{KCl}$ containing $0.02 \mathrm{M}$ Tris$\mathrm{HCl}$ buffer, $\mathrm{pH} 7.4$, by the use of a Potter homogenizer fitted with a loose Teflon pestle. The livers of 3 or 4 animals were pooled. The homogenate was centrifuged in a refrigerated centrifuge at $700 \mathrm{~g}$ for 10 minutes at $0 \mathrm{C}$, the supernatant at $9,000 \mathrm{~g}$ for 20 minutes at $0^{\circ} \mathrm{C}$ and the $9,000 \mathrm{~g}$ supernatant at $105,000 \mathrm{~g}$ for 70 minutes in succession. The microsomes obtained were resuspended in an isotonic $\mathrm{KCl}$ containing $0.02 \mathrm{M}$ Tris- $\mathrm{HCl}$ buffer, $\mathrm{pH} 7.4$, and recentrifuged at $105,000 \mathrm{~g}$ for 60 minutes. The washed microsomes did not contain any ethanol detectable by gas chromatography and were used as enzyme source in the amount of 5 to $6 \mathrm{mg}$ protcin.

\section{Enzyme assay}

Complete reaction mixtures of $3.0 \mathrm{ml}$ as a total volume were incubated in $30 \mathrm{ml} \mathrm{Er}$ lenmyer flasks in an atmosphere of air in a Dubnoff type metabolic shaker at $37 \mathrm{C}$ for 10 minutes. Duplicate incubation was carried out for each substrate concentration. The mixtures consisted of: $\mathrm{MgCl}_{2} \cdot 6 \mathrm{H}_{2} \mathrm{O}, 15$ /mmoles; NADP, 2 / /moles; glucose-6-phosphate $\mathrm{Na}_{3}, 15$ zmoles; Tris- $\mathrm{HCl}$, pH 7.4, $50 \mathrm{~mm}$; cell sap from control animals $0.5 \mathrm{ml}$ (about 13 $\mathrm{mg}$ protein); washed microsomes $0.5 \mathrm{ml}$ ( 5 to $6 \mathrm{mg}$ protein); aniline $0.5 \mathrm{ml}(0.02$ to $4 \mathrm{~mm}$ ). In the experiment with optimum $\mathrm{pH}$ shift $\mathrm{pH} 6.1$ or 8.1 was used for incubation medium. After termination of incubation, when the reaction was stopped by the addition of 1.2 $\mathrm{ml}$ of a siturated aqueous solution of $\mathrm{NaCl}$ the $p$-aminophenol production, formed for 10 minutes, was measured, to determine the p-hydroxylation of aniline, by the method of Guarino et a1. (3) under minor modification. After a $2 \mathrm{ml}$ aliquot was transferred to a 60 $\mathrm{ml}$ glass-stoppered centrifuge tube containing $0.6 \mathrm{~g}$ of solid $\mathrm{NaCl}$ and $20 \mathrm{ml}$ of diethylether with $1.5 \mathrm{v} / \mathrm{\%} \%$ isoamylalcohol, the tubes were mechanically shaken for 20 minutes. When the phases had been allowed to separate, a $10 \mathrm{ml}$ aliquot of the ether phase was transferred to a $60 \mathrm{ml}$ centrifuge lube of 4.0 $\mathrm{ml}$ of $0.5 \mathrm{M} \mathrm{K}_{3} \mathrm{PO}_{4}$ containing $1 \mathrm{w} / \mathrm{V} \%$ aqueous phenol, and the tubes were mechanically shaken for 10 minutes and centrifuged. Sixty minutes after the

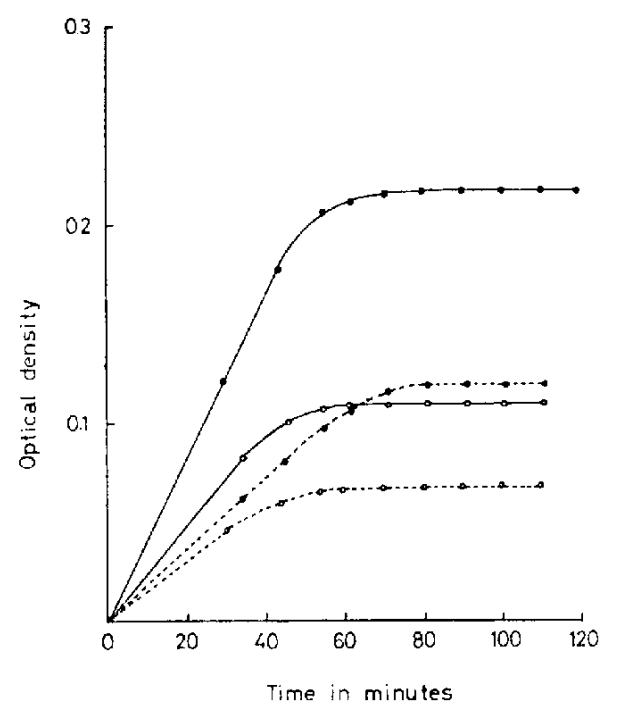

Fic. 1. The development of the colour of the aqueous phase with time. solid line : aniline $1 \mathrm{~mm}$ dotted line : aniline $0.1 \mathrm{~mm}$ open circle: ether phase $10 \mathrm{ml}$ closed circle : ether phase $20 \mathrm{ml}$ 
shaking ended, the optical density of the aqueous phase was measured at $620 \mathrm{~m} / 4$ in a Beckman spcetrophotometer. The colour of the aqueous phase, developing with time, became constant 60 minutes after the shaking (Fig. 1). Protein contents in cell sap and microsomes were estimated by the method of Lowry et al. (4), cristaline bovine serum albumin serving as the standard. The ethanol concentration in $9,000 \mathrm{~g}$ supernatant of liver homogenates was determined by gas chromatography according to the method of Duritz and Truitt (5), after the samples were treated only with $2 / 3 \mathrm{~N} \mathrm{H}_{2} \mathrm{SO}_{4}$.

For the determination of kinetic values for aniline hydroxylase, the graphycal procedures of Linewealver and Burk (6) and of Dixon (7) were used.

\section{RESULTS}

\section{Growth rate and the ratio of liver weight to body weight}

It was found that there was difference in the amounts of solid food taken by animals between the control group and the ethanol group. Though a control rat ate about 24 $\mathrm{g}$ of solid food a day, a rat of ethanol group, fed with $10 \%$ ethanol instead of water, ate about $19 \mathrm{~g}$, and, with $20 \%$ ethanol, only about $8 \mathrm{~g}$, a day.

TAlsLE 1. The ratio of liver weight to body weight in ethanol-treated rats ( 2 months).

\begin{tabular}{cccc} 
Group & $\begin{array}{c}\text { Body weight } \\
(\mathrm{g})\end{array}$ & $\begin{array}{c}\text { Liver weight } \\
(\mathrm{g})\end{array}$ & Liver weight body weight \\
Control $(21)$ & $320: 29$ & $11.9 \cdots 1.6$ & $0.037: 0.003$ \\
EtOH-1 (15) & $259: 27^{* *}$ & $10.9 \cdots 1.6$ & $0.042: 0.004^{*}$ \\
EtOH-2 $(15)$ & $255-30^{* *}$ & $9.8: 1.4^{* *}$ & $0.039=0.004$ \\
\hline
\end{tabular}

Values are the mean values -standard deviation.

The number of animals used for each value is in parentheses.

* significantly different from control and group EiOH-2, p 0.01

:** significantly different from control group $\mathrm{p} 0.01$

In the present experiments the growth rate of chronically ethanol-treated rats was significantly lower than that of controls $(p<0.01)$. The average body weight of a rat in group EtOH-1 and $\mathrm{EtOH}-2$ was $259 \mathrm{~g}$ and $255 \mathrm{~g}$ respectively, though that of control group was $320 \mathrm{~g}$ (Table 1). The average liver weight of group EtOH-1 and EtOH-2 was $10.9 \mathrm{~g}$ and $9.8 \mathrm{~g}$. whereas that of control group was $11.9 \mathrm{~g}$. The value of group EtOH-2 was significantly different from that of control group $(p<0.01)$. There is a significant difference in the ratio of liver weight to body weight between group EtOH-I and group EtOH2 , the ratio of the former higher than that of the latter $(p<0.01)$, whereas no difference was found between control rats and group EtoH-2 (Table 1).

There is no difference in protein contents of microsomes and cell sap between three groups.

2. Kinctic values for aniline hydroxylase

We measured the apparent values for the maximal velocity (Vmax) and Michachis constant $(\mathrm{Km})$ of the enzyme, to determine whether or not the increased activity of aniline hydroxylase resulted from an increase in protein synthesis. 
I) Our previous study revealed that the addition of ethanol in concentrations of 8.5 to $66 \mathrm{~mm}$ to the incubation medium calused an inhibition of $p$-hydroxylation of aniline, and the type of inhibition was competitive (2).

Since our preliminary studies showed that the kinetic values obtained from Lineweaver and Burk curves of the p-hydroxylation of aniline were the same whether washed microsomes or $9,000 \mathrm{~g}$ supernatant was used, we used washed microsomes as the enzyme source this time in order to avoid the inhibitory effect of cthanol in vitro. The washed microsomes did not contain any detectable ethanol.

TABLF 2. Kinetic values for aniline hydroxylase at $\mathrm{pH} 7.4$ (washed microsomes),

\begin{tabular}{ccc} 
Group & $\begin{array}{c}\text { Apparent } K m \\
(\mathrm{~mm})\end{array}$ & $\begin{array}{c}\text { Apparent Vmax } \\
(\text { moles } p \text {-aminophenol formed } \\
100 \mathrm{mg} \text { protein } 10 \mathrm{~min})\end{array}$ \\
Control & $0.057 \ldots 0.004$ & $2.12: 0.10$ \\
EtOH-1 & $0.060-0.008$ & $1.90=0.15^{*}$ \\
EtOH-2 & $0.054-0.010$ & $2.95-0.11^{* *}$ \\
\hline
\end{tabular}

Each mean represents six experiments.

Values are the mean values - standard deviation.

* significantly different from control, $\mathrm{p}<0.05$

*** significantly different from control, $p<0.01$

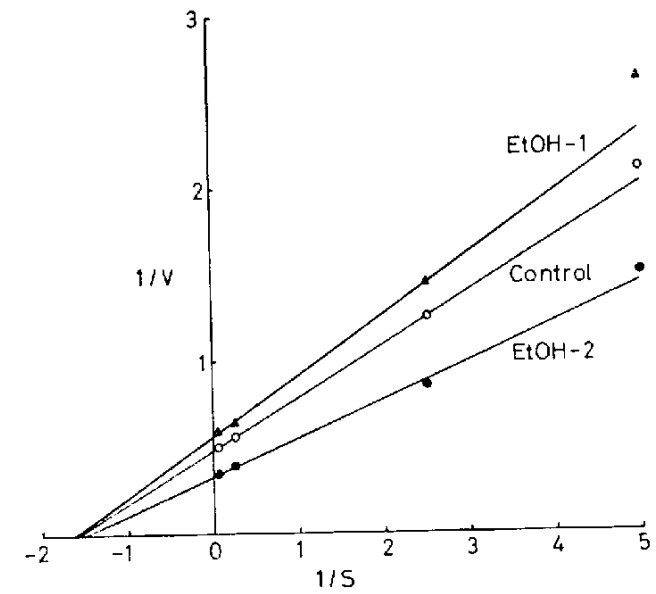

FIG. 2. A typical Lineweaver and Burk curve for aniline hydroxylase.

$\mathrm{S}$ : aniline $\mathrm{mm}$

$\mathrm{V}$ : , moles $p$-aminophenol formed/100 $\mathrm{mg}$ protein/10 minutes

The apparent $\mathrm{Km}$ and apparent Vmax obtained are presented in Table 2. No difference was seemingly found in the apparent $K m$ between the three groups (control rats, ElOH-1 and EtOH-2), the apparent Vmax of group EtOH-2 was about 1.5-fold increased in comparison with those of the other two groups (controls and EtOH-1). These results suggest that induction of aniline hydroxylase may occur in the livers of group EtOH-2.

Fig. 2 shows a typical Lincweaver and Burk curve. It is of great interest that the rate of $p$-hydroxylation of aniline in group EtOH-1 is mostly lower than in controls.

Some rats, though not so many, of group EtOH-2 did not contain any ethanol de- 
tectable by gas chromatography in their $9,000 \mathrm{~g}$ supernatant of liver homogenates. The rate of $p$-hydroxylation of aniline in them was slightly lower than in the rats with ethanol in their $9,000 \mathrm{~g}$ supernatant, but significantly higher than that of control rats (Table 3 ). 2) $p H$ shift

Rickert and Fouts (8) reported that the pH optimum for the metabolism in vitro of aniline was shifted from $\mathrm{pH} 7.0$ to $\mathrm{pH} 8.1$ by benzpyrene pretreatment. $\mathrm{Km}$ values for aniline hydroxylase were altered with the changes of $\mathrm{pH}$ in hepatic microsomes from either controls or benzpyrene-pretreated rats. Thus we experimented with the chronically ethanol-treated rats whether this phenomenon is observed or not.

The $\mathrm{pH}$ optimum for metabolism of aniline in vitro was not shifted after chronic ethanol treatment (Fig. 3).

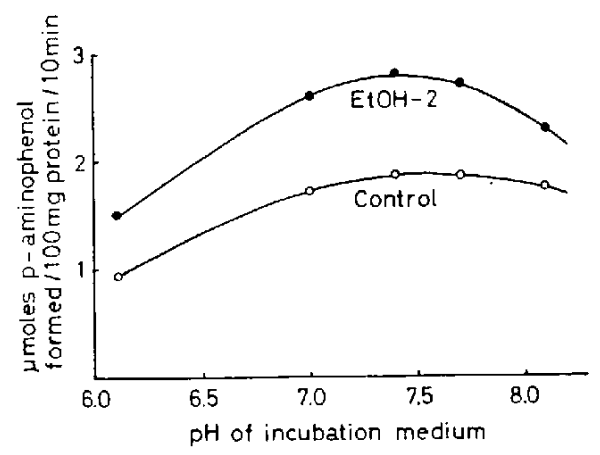

Fic. 3. The $\mathrm{pH}$ optimum for metabolism of aniline in vitro.

\section{DISCUSSION}

It is very interesting that the ratio of the liver weight to the body weight in the rats of group EtOH-1 is higher than that in the rats of group EtOH-2. However, at present, we have no explanation for this finding. There is no difference in protein contents of microsomes and cell sap between the three groups.

Of the chronically ethanol-treated rats which continued to drink ethanol ad libitum up to the lime of sacrifice (group EtOH-2), only the activity of aniline hydroxylase was approximately 2-fold increased, compared with that of control rats (1). In this experiment we used 9,000 g supernatant as an enzyme source. $9,000 \mathrm{~g}$ supernatant of the livers from the group EtOH-2 contained ethanol in concentrations of 5 to $20 \mathrm{mg} / \mathrm{dl}$. On the other hand, the addition of ethanol in a concentration of $8.5 \mathrm{~mm}$ to the incubation medium caused a competitive inhibition of $p$-hydroxylation of aniline (2). Thus, the microsomes from the livers of group EtOH-2 have still higher activity of p-hydroxylation of aniline, in spite of the presence of ethanol, as compared with that of control rats.

In the present experiments for kinetic studies, we used washed microsomes as the enzyme source for aniline hydroxylase in order to avoid the inhibitory effect of ethanol on aniline hydroxylation in vitro. The results obtained show that there is no difference in apparent $\mathrm{Km}$ for aniline hydroxylase between the three groups (controls, EtOH-1 and EtOH-2). In contrast, the apparent Vmax for aniline hydroxylase was approximatcly 1.5-fold increased in group EtOH-2 as compared with that in control rats. Furthermore, in most cases, the apparent Vmax in group EtOH-1 was lower than that in control rats. These findings suggest that the induction of aniline hydroxylase may occur in the rats of group $\mathrm{EtOH}-2$. 
Furthermore, the rate of $p$-hydroxylation of aniline of the rats in group EtOH-2 without any ethanol in $9,000 \mathrm{~g}$ supernatant was lower than that of the rats in the same group with ethanol in $9,000 \mathrm{~g}$ supernatant. This finding also supports the possibility of induction of aniline hydroxylase by ethanol.

The results obtained in the present experiments again appcar to disagree with those of Rubin and Lieber (9), as mentioned in the previous paper (1).

Kato and Gillette, and Kato demonstrated that starvation for 72 hours markedly impaired mctabolism of aminopyrine and hexobarbital by microsomes from male rats but enhanced metabolism of these substrates by microsomes from female rats. Aniline metabolism was enhanced in both sexes by starvation $(10,11)$. In the present experiments, a control rat ate about $24 \mathrm{~g}$ of solid food a day but a rat fed with $10 \mathrm{v} / \mathrm{v}^{\%} \%$ ethanol instead of water ate about $19 \mathrm{~g}$. Though further studies must be conducted in detail, the increase in the apparent $\mathrm{Vmax}$ in group EtOH-2 might be not due to the difference of amounts of food taken.

Recently Rickert and Fouts (8) reported that the pH optimum for the metabolism in vitro of aniline was shifted from $\mathrm{pH} 7.0$ to $\mathrm{pH} 8.1$ by benzpyrene pretreatment. $\mathrm{Km}$ values for aniline hydroxylase were altered by changes in $\mathrm{pH}$ with hepatic microsomes from either control rats or benzpyrene pretreated rats in their experiments. In the present experiments chronic ethanol treatment (both group EtOH-1 and EtOH-2) did not change the $\mathrm{pH}$ optimum for the metabolism in vitro of aniline.

\section{SUMMARY}

The present experiments were conducted to examine the kinetic behavior of aniline hydroxylase of rat liver microsomes after prolonged ethanol treatments.

The results obtained are as follows:

1. There is no difference in the apparent $K m$ between the three groups (control rats, group EtOH-1 and group EtOH-2).

2. The apparent Vmax in group EtOH-2 was about 1.5-fold increased, compared with those in control group and group EtOH-1.

3. The pH optimum for metabolism of aniline in vitro was not shifted after chronic ethanol treatment.

These findings suggest that the induction of aniline hydroxylase may occur in the rats of group EtOH-2.

\section{REFERENCES}

1) Nakanishi, S., Masamura, E., Tsukada, M., Mryazawa, T. and Matsumlra, R.: Med. J. Shinshu Univ. 15, 91 (1970)

2) Nakanishi, S., Masamura, E. and Tsumada, M.: Mcd. J. Shinshu Univ. 15, 11 (1970)

3) Gunrino, A.M., Gram, T.E., Gigon, P.L., Greene, F.E. and Gillette, J.R.: Mol. Pharmac. 5, $131(1969)$

4) Lowry, O.H., Roserrough, N.J., Farr, A.L. and Randall, R.J.: J. biol. Chem. 193, 265 (1951) 
5) Duritz, G. And Truitr, E.B., Jr.: Quart. I. Stud. Alcohol. 25, 498 (1964)

6) Lineweavi:R, H. Avd Burk, D.: J. Am. chom. Soc. 56, 658 (1934)

7) Dixon, M.: Biochem. J. 55, 170 (1953)

8) Rickfrt, D.E. A.vi Fouts, J.R.: Biochem. Pharmac, 19, 381 (1970)

9) Rubin, E. ANd Lifber, C.S.: Science, N.Y. 162, 690 (1968)

10) Kato, R. and Gillette, J.R.: J. Pharmac. exp. Ther. 150, 279 (1965)

11) Kato, R.: Jap. J. Phamac. 17, 181 (1967) 